\title{
Validation of a BOD5 alternative method
}

\author{
Audrey Magnin ${ }^{1}$, Mathieu Muller ${ }^{1}$, Alison Yoris ${ }^{1}$, Sabrina Guérin ${ }^{2}$, Vincent Rocher ${ }^{2}$ and Yves Dudal ${ }^{1}$ \\ ${ }^{1}$ ENVOLURE SAS, 1682 rue de la Valsière, 34184 Montpellier cedex 4, France \\ 2 SIAAP, Direction du Développement et de la Prospective, 82 Avenue Kléber, 92700 Colombes, France
}

\begin{abstract}
Résumé. La DBO5 (Demande Biochimique en Oxygène en 5 jours) permet de mesurer la charge en matière organique biodégradable d'un échantillon d'eau. Proposé pour la première fois en 1912 par la Royal Commission for Sewage Disposal en Angleterre, la DBO5 est désormais un paramètre incontournable à l'évaluation des performances d'une station d'épuration et au calcul des redevances pour pollution. Bien que simple d'utilisation, le bas-débit, la durée, le domaine de validité et l'encombrement du matériel rendent l'analyse DBO5 peu opérationnelle. Ainsi, des méthodes alternatives voient progressivement le jour afin de pallier à ces inconvénients. Cette publication présente la validation d'Enverdi-DBO, une solution alternative à la méthode standard, réalisée en microplaque 96-puits et délivrant un résultat en $48 \mathrm{~h}$. La technologie repose sur la mesure de la fluorescence d'une sonde redox exprimant l'activité catabolique microbienne. Cette validation se base sur l'analyse, selon la méthode Enverdi-DBO et la méthode standard, de 261 échantillons d'eaux usées et épurées provenant de différentes stations d'épuration urbaines. L'analyse statistique des résultats indique que les valeurs de DBO5 obtenues selon les deux méthodes sont équivalentes.
\end{abstract}

\section{Introduction}

Monitoring the level of organic pollution in raw and treated wastewater is crucial to ensure the efficiency of wastewater treatment and for ecosystem preservation. Biodegradable organic matter content in wastewater is mainly controlled by the BOD5 measurement. First recommended in 1912 by the Royal Commission for Sewage Disposal in England, BOD5 rapidly became a prevailing parameter. In 1936, the American Public Health Association Standard Committee adopted it as a reference indicator. In France, BOD5 is a standard parameter since 1998 (NF EN 1899-1 and -2).

BOD5 is now implemented worldwide to monitor most of the urban and industrial wastewater treatment plant (WWTP). It enables to assess the efficiency of organic matter removal by wastewater treatment processes. In addition, BOD5 is used for regulatory purposes. This parameter enters in the calculation of pollution discharge tax. The main shortcomings of BOD5 are the time of incubation, 5 days are often longer than the hydraulic retention time in WWTP, and the considerable high sample volume required. Several hundred of milliliters must be analyzed in triplicate to obtain an accurate BOD5. The resulting low-throughput of analysis involves a limited profitability for laboratories.

Effort has been made to offer more operational solutions to laboratories. The trend is to develop miniaturized, faster and high-throughput technologies relying, for example, on redox biosensors or on microbial fuel cells (1). However, the validation of alternative methods is generally performed on a reduced number of samples, collected from few sites, over a short period, which is insufficient to appraise the equivalence between the alternative and standard method performances.

Based on the tracking of a fluorescent redox mediator, the surrogate BOD5 method presented in this paper is an analytical kit developed and commercialized by Envolure (Montpellier, France). This turnkey and compact solution offers a rapid and high-throughput analysis: within 48 hours, up to 80 BOD5 measurements can be performed simultaneously in a 96-well microplate format. The surrogate method presents obvious operational and economic advantages compared to the standard one but its accuracy has to be strictly evaluated. In 2014, a first publication about the statistical comparison of EnverdiBOD and standard methods based on 109 samples was published (2). This paper presents a similar approach on an extended number of samples, 261 instead of 109, analyzed by 4 laboratories instead of 2 . The aim is to show sustained robustness over time, sample diversity and among different laboratories.

\section{Materials and method}

A panel of 261 samples from different urban wastewater treatment plants was collected by 4 laboratories in France and United States from 2013 to 2015. Most of them were frozen at $-20^{\circ} \mathrm{C}$ or stored at $4^{\circ} \mathrm{C}$ and analyzed within $48 \mathrm{~h}$ after collection. Both standard BOD5 and Enverdi-BOD were performed for all samples.

BOD5 reference value of these samples is obtained according to the standard method $5210 \mathrm{~B}$ in the US and NF EN 1899-1 in France. Inoculum used was either a natural (urban WWTP input) or synthetic (PolySeed) bacterial consortium.

The Enverdi-BOD kit commercialized by Envolure contains all required reagents and standard solutions as well as 96-well microplates and microplate seals. Only natural source of bacteria was used as inoculum for Enverdi-BOD analysis. For this purpose, an urban WWTP inputs was selected by each laboratory. This sample was either filtrated at $1.2 \mu \mathrm{m}$, or centrifuged at $5000 \mathrm{~g}$ for 30 $\mathrm{s}$, and the filtrate or supernatant was therefore used for sample inoculation. Samples was previously diluted to fall into the quantification zone, from 3 to about $110 \mathrm{mg} \mathrm{O} / \mathrm{L}$, and partially sterilized through a thermal pretreatment consisting in a 10 min heating step at $120{ }^{\circ} \mathrm{C}$ followed by a $10 \mathrm{~min}$ cooling step at $4{ }^{\circ} \mathrm{C}$. This pretreatment is performed in a 
Table 1 Statistical results from the linear regression and conclusion about the equivalence of the two methods

\begin{tabular}{|c|c|c|c|c|c|c|}
\hline & \multirow{2}{*}{\multicolumn{3}{|c|}{$\begin{array}{l}\text { Linear regression } \\
(y=a x+b) \\
\alpha=0.05\end{array}$}} & \multirow{2}{*}{\multicolumn{2}{|c|}{$\begin{array}{l}\text { Linear regression } \\
(y=a x) \\
\alpha=0.05\end{array}$}} & \multirow[t]{3}{*}{$\begin{array}{l}\text { Equivalence } \\
\text { test }\end{array}$} \\
\hline & & & & & & \\
\hline & $R^{2}$ & $\begin{array}{l}a \\
{[95 \% \mathrm{CI}]}\end{array}$ & $\begin{array}{l}b \\
{[95 \% \mathrm{CI}]}\end{array}$ & $R^{2}$ & $\begin{array}{l}a \\
{[95 \% \mathrm{CI}]}\end{array}$ & \\
\hline $\begin{array}{l}\text { Linear regression } \\
\text { test }\end{array}$ & 0.935 & 0.990 & 1.445 & 0.935 & 0.995 & Pass \\
\hline$n=261$ & & {$[0.958 ; 1.021]$} & {$[-3.937 ; 6.827]$} & & {$[0.9720 ; 1.019]$} & \\
\hline
\end{tabular}

polypropylene microplate covered by an aluminum seal. Once the reagents, The inoculum and the pretreated samples mixed together in polystyrene microplate wells, fluorescence measurements, shaking and incubation under aerobic conditions were completed using a microplate reader Flx800 supplied by Biotek company.

Equivalence between BOD5 values measured by Enverdi-BOD and standard methods was tested through the three most common statistical tests used for analytical methods comparison: the linear least-squares regression, the Bland and Altman approach, and the Wilcoxon test. These tests were performed using the software XLSTAT (Addinsoft, France). With the linear least-squares regression (3), the assumption $\mathrm{y}=\mathrm{ax}+\mathrm{b}$, with the slope $\mathrm{a}$ being not significantly different from 1 and the ordinate $b$ not significantly different from 0 , was tested. Given that $y$ represents the Enverdi-BOD measurements and $\mathrm{x}$ represents the standard BOD5, both methods are statistically equivalent when the previous assumption is verified. The confidence interval on the calculation of a and $b$ was set at $95 \%(\alpha=0.05)$. The particularity of the linear least-squares regression is that the weight of the high BOD5 values in the determination of $a$ and $b$ is higher than the weight of the low BOD5 values since the absolute distances between the $\mathrm{y}$ values and the regression line, which are minimize during the process, tend to be higher for the high BOD5 values compared to the low ones.

With the Bland and Altman approach (4), the assumption $y=a x+b$, with the slope $a$ not significantly different from 0 and the ordinate $b$ not significantly different from 0 , was tested. Given that $y$ represents the normalized error of the Enverdi-BOD method versus the standard method, defined as $y=$ normalized error $=$ Enverdi BOD5 - Standard BOD5

Standard method

BOD5 values calculated from both methods, the result $a$ not significantly different from 0 means that $y$ is not significantly different from a constant value. In this case, the best parameters describing this constant value are the average normalized error $(\bar{y})$ or the median normalized error $(m)$. If $\bar{y}$ and $m$ are not significantly different from 0 , it can be concluded that the normalized error is equally distributed around the $\mathrm{x}$ axis and that there is not systematic overestimation or underestimation of the Enverdi-BOD method against the standard BOD5 method. The confidence interval on the calculation of $a, b$ and $m$ was set at $95 \%(\alpha=0.05)$. The nullity of $\bar{y}$ was tested through a t-test with a risk $\alpha=0.05$ (5). The particularity of the Bland and Altman approach is that the weight of the low BOD5 values in the determination of $a, \bar{x}$ and $m$ is higher than the weight of the high BOD5 values since the normalized errors tend to be higher for the low BOD5 values compared to the high ones.

The Wilcoxon test (6) indicates how the median difference between pairs $(y-x)$ is significantly equal to 0 (H0) or significantly different from 0 (H1). Given that $y$ represents the BOD5 measurements obtained from Enverdi-BOD and $x$, the BOD5 measurements obtained from the standard method, if $\mathrm{H} 0$ cannot be rejected with the risk of $\alpha=0.05$, it means that the two methods are statistically equivalents. Since the test requires the ranking of the absolute differences between pairs from the smallest value to the highest one, without considering the DBO5 value of the samples, the weight of the low and high DBO5 values are similar.

\section{Results and discussion}

Figure 1 Correlation between the surrogate and reference BOD5 values. The Upper Unc. and Lower Unc. represent, respectively, the absolute superior and inferior uncertainty limits usually admitted on the BOD5 values delivered by the standard method.

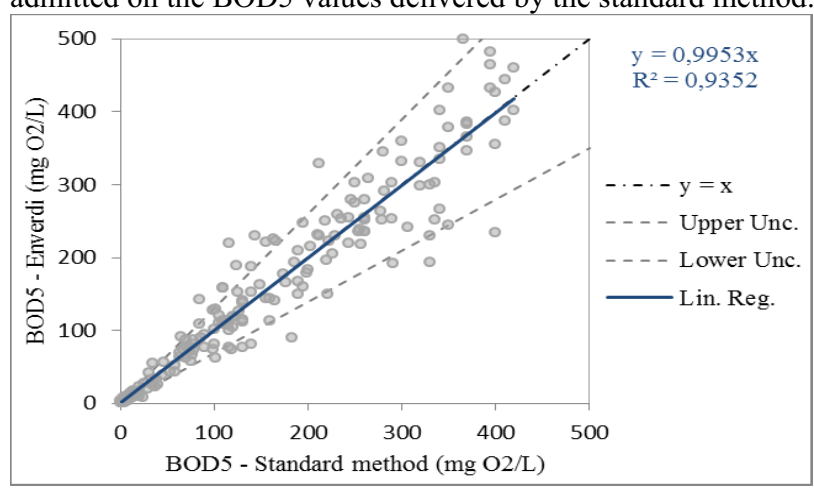

BOD5 ranged from below the detection limit $(3 \mathrm{mg}$ O2/L) to $500 \mathrm{mg} \mathrm{O2/L} \mathrm{(Results} \mathrm{and} \mathrm{discussion}$

Figure 1). Samples are homogeneously distributed over this concentration interval. Uncertainties generally admitted for the standard BOD5 methods are $40 \%$ for BOD5 between 3 and $6 \mathrm{mg} \mathrm{O2/L}$ and 30\% for BOD5 above $6 \mathrm{mg} \mathrm{O2/L}$ (Results and discussion

Figure 1 and Figure 2). In 2014, an estimation of EnverdiBOD uncertainties according to the norm NF-ISO 11352 was achieved by the SIAAP (Greater Paris Sewage authorities). This study revealed uncertainties comparable to those of the standard method. Considering these uncertainties, only 12 BOD5 value significantly different from the standard samples over the 261 quantified showed 
Table 2 Statistical results from the Bland and Altman test and conclusion about the equivalence of the two methods

\begin{tabular}{|c|c|c|c|c|c|c|c|}
\hline & \multicolumn{3}{|c|}{$\begin{array}{l}\text { Linear regression }(\mathrm{y}=\mathrm{ax}+\mathrm{b}) \\
\alpha=0.05\end{array}$} & \multirow{2}{*}{$\begin{array}{l}\text { Median } \\
\text { Nor.err. (\%) } \\
\alpha=0.05 \\
m \\
{[95 \% \mathrm{CI}]}\end{array}$} & \multirow{2}{*}{$\begin{array}{l}\begin{array}{l}\text { Average } \\
\text { Nor.err. (\%) }\end{array} \\
\alpha=0.05 \\
\bar{y} \\
{[95 \% \mathrm{CI}]}\end{array}$} & \multirow{2}{*}{$\begin{array}{l} \\
\mathrm{p} \text { value } \\
\mathrm{H}_{0}: \bar{y}=0\end{array}$} & \multirow{2}{*}{$\begin{array}{l}\begin{array}{l}\text { Equivalence } \\
\text { test }\end{array} \\
\text { Pass/fail }\end{array}$} \\
\hline & $R^{2}$ & $\begin{array}{l}a \\
{[95 \% \mathrm{CI}]}\end{array}$ & $\begin{array}{l}b \\
{[95 \% \mathrm{CI}]}\end{array}$ & & & & \\
\hline $\begin{array}{l}\text { Bland and } \\
\text { Altman test }\end{array}$ & n.r. & $-0,013$ & 3.630 & 3.306 & 2.100 & 0.328 & Pass \\
\hline$n=261$ & & {$[-0.047 ; 0.020]$} & {$[-2.062 ; 9.322]$} & {$[-0.847 ; 6.897]$} & ]-2.117;6.318[ & $\mathrm{H}_{0}$ not rejected & \\
\hline
\end{tabular}

Figure 2 Bland and Altman graphical representation of the normalized errors of the surrogate method against the reference method as a function of the average BOD5 obtained from both methods. The Upper Unc. and Lower Unc. represent, respectively, the relative superior and inferior uncertainty limits usually admitted on the BOD5 values delivered by the standard method.

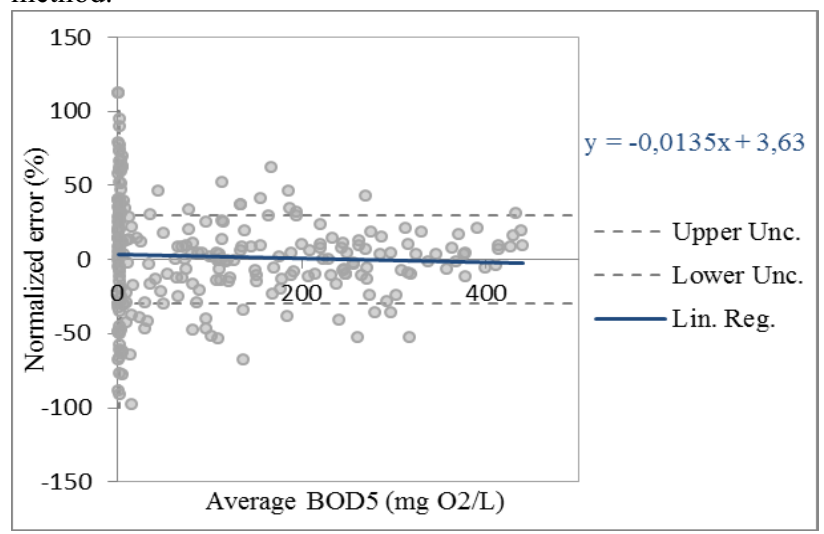

an Enverdi BOD5 value. Requirement of French water agency concerning alternative methods approval is a similitude higher than $90 \%$ (ref). With $97 \%$ of similarity, this dataset amply fulfills the agency prerequisite.

\section{To strengthen this equivalence, linear least-squares regression test was performed (Results and discussion}

Figure 1). Two equations were generated; an affine equation $(y=a x+b)$ and, as 0 is included in the confidence interval of $b$, an equation with the ordinate fixed at 0 $(y=a x)$ (Table 1). Slopes of both equations revealed no significant difference from 1 with a confidence interval of $95 \%$. Coefficient of determination is 0.93 in both case, meaning that the dispersion around the $\mathrm{y}=\mathrm{x}$ axis is limited.

In order to statistically evaluate the method equivalence promoting the weight of low BOD5 value, the Bland and Altman approach was executed (Figure 2). Exploitation of the normalized errors limits the influence of high BOD5 contrary to the linear regression test. Bland and Altman result indicates a slope non-statistically different from 0 suggesting a proportional bias over the sample concentration range. For the ordinate, 0 is in the confidence interval of $95 \%$. Both the median and the average of the normalized errors are non-significantly higher than 0 .

In conclusion, there is no systematic over- or underestimation of the BOD5 with Enverdi-BOD $(b=0)$. The accuracy of this method is attested by the Bland ad Altman test.
The Wilcoxon test confirms the conclusion of the two preceding tests. The risk to conclude that the median difference between pairs $(\mathrm{y}-\mathrm{x})$ is not equal to 0 the $p$ value is 0.62

\section{Conclusion}

An increased number of analytical laboratories get interested in alternative BOD5 method to cope with the pretty low throughput of the standard method. EnverdiBOD appears to be particularly convenient for this purpose; the microplate format combined with a reduced time of incubation enables a high-throughput of analysis. Four laboratories took part in the cross-validation presented in this paper. The three statistical tests performed on 261 pairs of BOD5 revealed a strict correlation. These results consolidate the equivalence attested in Muller et al. (2014) (2).

The confirmed strength of Enverdi-BOD offers promising prospects on regulatory features. Procedure for method certification has been well engaged in France. Enverdi-BOD could be approved by authorities in a near future.

\section{References}

1. S Jouanneau, L Recoules, MJ Durand, A Boukabache, V Picot, Y Primault A Lakel, M Sengelin, B Barillon, G Thouand, Water Res, 49, 62-82. (2014)

2. M Muller, S Bouguelia, RA Goy, A Yoris, J Belin, P Meche, V Rocher, S Mertens, Y Dudal, Environ. Sci. Pollut. Res., 1-4 (2014).

3. C Tan, Y Charles, B Iglewicz, Technometrics, 41, 192-201 (1999)

4. M Bland, D Altman, Stat. meth. in medical res., 8, 135-160 (1999)

5. R Sokal, J Rohlf, Biometry. The principles and practice of statistics in biological research, (1981)

6. F Wilcoxon, Biometrics bull., 80-83 (1945) 